\title{
EDITORIAL
}

\section{Rapid response teams improve outcomes: we are not sure}

\author{
Julia Wendon ${ }^{1}$, Carol Hodgson ${ }^{2}$ and Rinaldo Bellomo ${ }^{2^{*}}$
}

(C) 2016 Springer-Verlag Berlin Heidelberg and ESICM

Rapid response teams (RRTs) have been systematically introduced into hospital practice in many countries (Australia, New Zealand, UK, USA, Canada, the Netherlands, Denmark and Sweden) under a variety of names including "medical emergency teams", "outreach teams" or "emergency response teams". However, they remain either absent or only sporadically available in a small minority of centres in most of Western Europe and elsewhere in the world. Irrespective of their nomenclature, the aim of RRTs is to improve the safety of deteriorating ward patients [1]. The RRT approach is based on (a) identification of patients at risk; (b) early notification of a team; (c) rapid intervention by the team and (d) audit of the system's performance [2].

Despite their widespread introduction in Anglo-Nordic countries, it remains controversial whether RRTs are effective in achieving their stated aims. Importantly, their introduction has not been supported by large multicentre randomised controlled trials. Rather, it has been supported by overwhelming evidence that many hospital patients experience an episode of unpredicted clinical deterioration, that the response to such deterioration is often suboptimal (in the areas of identification, action and intervention) and that, by logical inference, early intervention by a suitably trained, skilled, equipped team would likely increase safety and improve the outcomes of such deteriorating ward patients.

After their introduction, their continued application and uptake by English-speaking and Nordic countries have been sustained by limited evidence. Such evidence

\footnotetext{
*Correspondence: rinaldo.bellomo@austin.org.au

${ }^{2}$ Australian and New Zealand Intensive Care Research Centre, School of Public Health and Preventive Medicine, Monash University, Melbourne, Australia

Full list of author information is available at the end of the article
}

Contrasting viewpoints can be found at: doi:10.1007/s00134-016-4219-5 and doi:10.1007/s00134-016-4246-2. derives from multiple before-and-after single or multiple centre studies and meta-analyses of available data [3]. These studies have typically reported a reduction in hospital cardiac arrests, greater effect with greater "RRT dose" (RRT reviews/1000 patient admissions) and variable impact on mortality. However, a major multicentre cluster randomised controlled trial called MERIT failed to demonstrate a benefit. Moreover, meta-analyses have been variable in their conclusions; several authors have questioned whether tangible benefits really exist and suggested that further higher level research and trials are required [2]. In this setting, a major practice question for many institutions in 2016, therefore, is whether the evidence is now strong enough to be sure that their introduction is clearly justified or, instead, so weak or poor that their introduction is likely a pointless and expensive misallocation of resources.

In this regard, we believe that the evidence available to support the introduction of RRTs is inconclusive and that we cannot be sure that such teams improve patient outcomes. Put in legal terms there is "reasonable doubt" about their effectiveness. This is because there have not been multicentre randomised controlled trials of sufficient power and methodological rigour. Such lack of suitable level 1 evidence is not deliberate. It is simply due to the inherent difficulties associated with designing and executing such a trial. They include the inability to blind treatment; the presence of contamination; the ethical issues surrounding the allocation of patients to a control group; the logistic challenges of training; maintaining and deploying such a team for the purpose of a trial 24/7, and the known need for such systems to become accepted and operative for a period of time before they are applied optimally to deliver an effective "treatment response". In an attempt to overcome at least some of these challenges, investigators resorted to conducting a clusterrandomised controlled trial, where hospitals instead of

\section{Springer}


individuals were randomised to introduce or not introduce an RRT. This study, called MERIT [4], remains a milestone effort in this regard and has spawned multiple papers seeking to investigate several key and often unappreciated aspects of its findings [5].

On its primary analysis, the MERIT trial did not find any evidence of an effect of RRTs on cardiac arrests, mortality or ICU admissions. The MERIT trial, however, was not a "negative" trial as several commentators have argued; it was an "inconclusive" trial. This is because the number of clusters and the marked variance in outcomes from hospital to hospital led to a grossly underpowered trial exposed to a very high chance of type II error. Moreover, as studies of RRTs have accrued over time since then, several additional important logistic aspects have emerged that could not be adjusted for in the design and execution of MERIT. They include the need for a long run-in period; the benefit of team training; the advantage of ensuring critical care medical input; the need to deliver a sufficient dose of intervention (number of calls/1000 patients); the need to optimise the performance of the afferent limb of the system (the component responsible for calling the team); the need for sufficient administrative and political institutional support, and, finally, the full commitment of the critical care team and department to ensure performance, monitoring and continued improvement of the RRT. Subsequent studies, which analysed the data from different perspectives, have argued that there was in fact an effect on cardiac arrests and mortality [2] (Table 1). Unfortunately, however, such post hoc analyses carry a significant risk of type I error, leaving clinicians still uncertain about the presence of a true beneficial effect.

Given the above observations, we cannot be sure whether RRTs deliver better patient outcomes. In many ways, studies that report a clear effect describe what RRTs can do under optimal operating circumstances but not necessarily what they will actually do under average or perhaps even suboptimal levels of clinician and institutional commitment or support. Importantly, some of these optimal conditions include the organizational functionality of the whole hospital system, its

\section{Table 1 Post hoc studies using the MERIT study database}

\begin{tabular}{|c|c|c|}
\hline Primary author, journal, year & Study question using MERIT data & Key findings of study \\
\hline $\begin{array}{l}\text { Chen J } \\
\text { Crit Care Med } \\
2015\end{array}$ & $\begin{array}{l}\text { Was delay }>15 \text { min in responding to documented deterio- } \\
\text { ration associated with risk? }\end{array}$ & $\begin{array}{l}\text { Introducing RRTs decreased response delays. Delayed calls } \\
\text { more common at night. Delayed calls associated with } \\
\text { increased risk of ICU admission and death }\end{array}$ \\
\hline $\begin{array}{l}\text { Chen J } \\
\text { J Crit Care } \\
2015\end{array}$ & What were the triggers for emergency calls & $\begin{array}{l}\text { The most common trigger was that staff members were } \\
\text { "worried" about the patient ( } 35 \text { times more likely than in } \\
\text { control hospitals), while respiratory and cardiovascular or } \\
\text { multisystem deterioration were less common triggers in } \\
\text { RRT hospitals }\end{array}$ \\
\hline $\begin{array}{l}\text { Chen J } \\
\text { Trials } \\
2009\end{array}$ & $\begin{array}{l}\text { Was baseline hospital performance associated with RRT } \\
\text { effect? }\end{array}$ & $\begin{array}{l}\text { The worse the baseline performance of a given the } \\
\text { hospital, the greater the impact on cardiac arrests, ICU } \\
\text { admissions and mortality of introducing an RRT }\end{array}$ \\
\hline $\begin{array}{l}\text { Chen J } \\
\text { Resuscitation } \\
2009\end{array}$ & What was the nature and timing of RRT interventions? & $\begin{array}{l}\text { Almost all RRT interventions required critical care skills, } \\
\text { most happened in the morning and the median duration } \\
\text { was } 25 \text { min }\end{array}$ \\
\hline $\begin{array}{l}\text { Chen J } \\
\text { Crit Care Med } \\
2009\end{array}$ & $\begin{array}{l}\text { What was the relationship between early emergency team } \\
\text { calls and serious adverse events? }\end{array}$ & $\begin{array}{l}\text { For every } 10 \% \text { increase in early activation of emergency } \\
\text { teams there was a significant } 2.2 / 10,000 \text { admissions } \\
\text { reduction in cardiac arrests and a significant 0.94/10,000 } \\
\text { reduction in unexpected deaths }\end{array}$ \\
\hline $\begin{array}{l}\text { Chen J } \\
\text { Resuscitation } \\
2009\end{array}$ & How did RRTs affect the documentation of vital signs? & $\begin{array}{l}\text { RRTs increased the documentation of respiratory rate, and } \\
\text { blood pressure prior to emergencies }\end{array}$ \\
\hline $\begin{array}{l}\text { Chen J } \\
\text { Resuscitation } \\
2008\end{array}$ & How did RRTs affect not for resuscitation (NFR) orders? & $\begin{array}{l}\text { RRTs increased the rate of NFR orders at the time of an } \\
\text { emergency where a cardiac arrest had not yet occurred } \\
\text { by ten times }\end{array}$ \\
\hline $\begin{array}{l}\text { Cretikos M } \\
\text { Crit Care Resusc } \\
2008\end{array}$ & $\begin{array}{l}\text { How did the extent of RRT implementation vary across } \\
\text { hospitals? }\end{array}$ & $\begin{array}{l}\text { The extent of implementation of RRTs varied significantly } \\
\text { and was associated with knowledge of RRT trigger crite- } \\
\text { ria, understanding of RRT purpose, hospital's readiness } \\
\text { for change, and attitude toward the new system among } \\
\text { staff members }\end{array}$ \\
\hline $\begin{array}{l}\text { Cretikos M } \\
\text { Crit Care Resusc } \\
2007\end{array}$ & $\begin{array}{l}\text { How well do vital signs criteria identify patients at risk of a } \\
\text { major adverse event? }\end{array}$ & $\begin{array}{l}\text { A heart rate }>140 \text { beats/min, a respiratory rate }>36 \\
\text { breaths/min and systolic blood pressure }<90 \mathrm{mmHg} \text { and } \\
\text { a two-point reduction in Glasgow Coma Scale had a high } \\
\text { specificity but only } 49 \% \text { sensitivity }\end{array}$ \\
\hline
\end{tabular}


clinical communication processes and commitment to continuous improvement processes. In supportive systems, RRTs will likely impact significantly on clinical outcomes, while in less functional systems any effect is likely to be lost.

However, despite the above considerations, the key question may well not be are we are sure or not sure that RRTs "work"? The key question may instead be how sure do we need to be that RRTs work before we introduce them? In this commentary, we have used a legal analogy and have argued that we are not sure about their effectiveness beyond "reasonable doubt". However, the law also uses different levels of evidence according to different situations and, for civil cases, damages are paid to the plaintiff if the "preponderance of the evidence" supports the case. In this case, it is clear that the preponderance of evidence is supportive and much greater than the evidence behind trauma teams or, indeed, cardiac arrest teams, which now operate every day in almost all major hospitals in developed countries in the absence of any controlled trials.

Whether such evidence for RRTs is sufficiently compelling for clinicians, institutions and health care systems to introduce them, however, is ultimately a question that can only be addressed locally. In this regard, most AngloNordic countries have already "voted with their feet". As the patient safety agenda spreads throughout Europe, it seems likely that other countries will also progressively adopt similar systems in the future. Yet RRTs, as with any safety initiative, must always also address the need for hospital-wide and system-wide continuous improvement methodology and implementation.

\section{Author details}

${ }^{1}$ Liver Intensive Therapy Unit, Institute of Liver Studies, King's College Hospital, London, UK. ${ }^{2}$ Australian and New Zealand Intensive Care Research Centre, School of Public Health and Preventive Medicine, Monash University, Melbourne, Australia.

Compliance with ethical standard

Conflicts of interest

On behalf of the authors, the corresponding author states that there is no conflict of interest.

Received: 27 January 2016 Accepted: 27 January 2016

Published online: 5 February 2016

References

1. Frost SA, Chapman A, Aneman A et al (2015) Hospital outcomes associated with introduction of a two-tiered response to the deteriorating patient. Crit Care Resusc 17:77-82

2. Jones DA, DeVita MA, Bellomo R (2011) Rapid-response teams. N Engl J Med 365(2):139-146

3. Maharaj R, Raffaele I, Wendon J (2015) Rapid response systems: a systematic review and meta-analysis. Crit Care 19:254

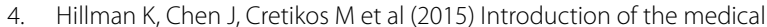
emergency team (MET) system: a cluster-randomised controlled trial. Lancet 365:2091-2097

5. Chen J, Bellomo R, Flabouris A et al (2015) Delayed emergency team calls and associated hospital mortality: a multicenter study. Crit Care Med 43:2059-2065 